\title{
Хроническая обструктивная болезнь легких и хроническая сердечная недостаточность: особенности совместной терапии
}

\author{
Первый МГМУ им. И.М.Сеченова, кафедра клинической фармакологии и пропедевтики внутренних болезней: 109240, Москва, ул. Яузская, 11, к. 5
}

\section{V.V.Arkhipov \\ Chronic obstructive pulmonary disease and chronic heart failure: particularities of co-treatment}

Key words: chronic obstructive pulmonary disease, chronic heart failure.

Ключевые слова: хроническая обструктивная болезнь легких; хроническая сердечная недостаточность.

Сочетание хронической обструктивной болезни легких (ХОБЛ) и хронической сердечной недостаточности (ХСН) представляет собой серьезную проблему для диагностики и лечения. Эти заболевания объединяют общие факторы риска и схожие черты клинической картины. Прогрессирование ХОБЛ способно обусловить развитие легочной гипертензии, а выраженное системное воспаление, характерное для части больных ХОБЛ, может усиливать эндотелиальную дисфункцию и усугублять течение ХСН. Кроме того, некоторые препараты, без которых трудно представить терапию ХСН, традиционно противопоказаны больным ХОБЛ, а бронхолитики, в свою очередь, могут оказывать неблагоприятное действие на сердечно-сосудистую систему.

В последние годы некоторые вопросы, связанные с фармакотерапией сочетанной респираторной и сердечно-сосудистой патологии были пересмотрены, в частности, обсуждалась возможность назначения $\beta$-блокаторов больным ХОБЛ, были обнаружены кардиопротективные эффекты ингаляционных глюкокортикостероидов (ГКС) и положительное влияние статинов на течение ХОБЛ.

Целью настоящего обзора является обобщение имеющейся информации по вопросам диагностики и лечения ХСН у больных ХОБЛ.

\section{Эпидемиология}

Распространенность ХСН у больных ХОБЛ составляет от 10 до $46 \%$ [1]. При этом сочетание ХОБЛ и ХСН сопровождается более высокой смертностью от сердечно-сосудистых причин и более частой госпитализацией [2]. У больных ХСН ХОБЛ также диагностируется чаще, чем у больных с другими сердечно-сосудистыми заболеваниями [3]. Среди больных ХCH, принимавших участие в когортных или рандомизированных клинических исследованиях ХСН, доля больных ХОБЛ составляла от 11 до $52 \%$ [4]. Сочетание ХОБЛ и ХСН чаще отмечается у мужчин и среди жи- телей городов. Интересно отметить, что кардиологи наблюдают таких пациентов на 6-11 \% реже, чем врачи общей практики. Возможно, это объясняется тем, что "узкие" специалисты менее ориентированы на диагностику "непрофильной" патологии.

\section{Клиническая картина}

Диагностика сочетанных случаев ХОБЛ и ХСН и определение "удельного веса" каждого из заболеваний в тяжести состояния больного порой представляют значительные сложности для врача. Во-первых, ХСН и ХОБЛ имеют несколько общих симптомов, типичных для обоих заболеваний, - одышка и кашель, которые усиливаются в положении лежа. И для ХОБЛ и для ХСН характерны увеличение частоты дыхания, отек голеней, гепатомегалия и вздутие яремных вен.

Рентгенологические симптомы - обеднение легочного сосудистого рисунка на периферии - также свойственно и для ХОБЛ (эмфизема) и для ХСН (легочная гипертензия). В ряде случаев рентгенологические признаки ХОБЛ и ХСН могут маскировать друг друга. Так, для ХСН свойственно увеличение кардиоторакального индекса (отношение поперечника сердца к максимальной ширине грудной клетки), однако при ХОБЛ гиперинфляция, напротив, снижает кардиоторакальный индекс [5]. Диффузные изменения паренхимы легкого у больных ХОБЛ затрудняют выявление рентгенологических признаков отека легких [6].

Повышенная воздушность легких может снижать информативность эхокардиографии (ЭхоКГ) у 10,4 \% больных ХОБЛ [7], но среди больных с очень тяжелым течением заболевания ЭхоКГ неинформативна у половины пациентов [8]. В таких случаях для измерения размеров камер сердца и оценки сократительной способности миокарда лучше использовать магнитно-резонансную томографию сердца [9].

В проведении дифференциального диагноза между ХОБЛ и ХСН может оказаться полезным исследование натрийуретического пептида: низкие 
(< 100 пг / мл) значения натрийуретического пептида делают диагноз ХСН маловероятным [10].

Бронхообструкция также не является симптомом, специфическим исключительно для ХОБЛ. Задержка жидкости у больных с декомпенсацией ХСН может вызывать значимую бронхообструкцию, вплоть до снижения объема форсированного выдоха за 1-ю с $\left(\mathrm{OФB}_{1}\right)$ на $45 \%$, а применение диуретиков у таких больных, напротив, приводит к нормализации величины ОФВ 1 [11, 12].

\section{Прогноз}

В целом ряде исследований было показано отрицательное влияние ХОБЛ на прогноз у больных сердечно-сосудистыми заболеваниями. Например, в исследовании VALIANT у 1258 (8,6 \%) больных, перенесших инфаркт миокарда, имелись признаки ХОБЛ. Летальность среди таких больных за 2 года исследования составила $30 \%$, в то время как у больных без обструктивных заболеваний летальность не превышала 19 \%. Исследование VALIANT выявило еще одну интересную закономерность: у больных, получавших $\beta$-блокаторы, смертность оказалась ниже, независимо от наличия ХОБЛ.

Представляют интерес результаты мета-анализа D.Sin et al. [13], в котором было показано, что у больных с наиболее низкими показателями ОФВ 1 риск смерти от сердечно-сосудистых причин на 77 \% выше (отношение рисков (ОР) - 1,77 [1,56-1,97]), чем у больных с более высокими значениями ОФВ

\section{Роль системного воспаления в патогенезе ХCH и ХОБЛ}

Воспаление дыхательных путей у больных ХОБЛ нередко приобретает системный характер. При этом в крови больных обнаруживаются высокая концентрация интерлейкина-6 (IL-6), фактора некроза опухоли- $\alpha$ (TNF- $\alpha)$ и С-реактивного белка (CRP), который синтезируется гепатоцитами под влиянием IL-6. Наличие системного воспаления существенно увеличивает тяжесть заболевания и повышает риск обострения ХОБЛ. Например, в когорте из 1302 больных с бронхообструкцией, принимавших участие в Copenhagen City Heart Study, при уровне CRP $>3$ мг / л риск госпитализации по поводу ХОБЛ оказался на 40 \% выше, а риск смерти от ХОБЛ - в 2,2 раза выше, чем у больных с уровнем CRP $<3$ мг / л [14]. В другом исследовании максимальный уровень CRB отмечался у наиболее тяжелых больных ХОБЛ и у пациентов, продолжающих курить [15]. У больных с ранним (до 50 лет) развитием ХОБЛ отмечается более высокий уровень системного воспаления (оценивался по IL-8 и CRP) и более высокий риск летального исхода [16]. Более выраженное системное воспаление у больных ХОБЛ ассоциировано с наиболее быстрыми темпами снижения ОФВ 1 и прогрессирования заболевания [17]. Быстрое снижение ОФВ особенно связано с высокими значениями IL-6 [18]. Системное воспаление имеет значение уже на ранних стадиях формирования ХОБЛ, так у "бессимптомных" лиц, у которых при спирометрии было отмечено снижение ОФВ ${ }_{1}<80 \%$ от должного, отмечался более высокий уровень CRP, чем у лиц с нормальными показателями ОФВ 1 [19].

Системное воспаление у больных ХОБЛ оказывает неблагоприятное влияние на состояние сердечнососудистой системы. В ряде исследований было показано, что TNF- $\alpha$, CRB и IL-6, воздействуя на эндотелий сосудов, могут облегчать депозицию компонентов атеросклеротических бляшек и способствовать прогрессированию атеросклероза [20].

Исследование маркеров системного воспаления у 6629 больных ХОБЛ, принимавших участие в Third National Health and Nutrition Examination Survey показало, что у больных с выраженной бронхообструкцией в $2,18(1,46-3,27)$ раза чаще отмечается повышенный уровень CRP. Высокий уровень CRP в этом исследовании коррелировал с риском появления ишемических изменений на ЭКГ [21]. Однако системное действие CRB, по-видимому, не ограничивается неблагоприятным влиянием только на механизмы атерогенности. Так, в опытах in vitro $\mathrm{CRB}$ ингибировал активность эндотелиальной NO-синтетазы, нарушая синтез оксида азота ${ }^{1}$ и вызывая тем самым эндотелиальную дисфункцию [22, 23].

Исследование маркеров воспаления у 732 пожилых участников Фрамингемского исследования показало, что у лиц без инфаркта миокарда и без признаков XCH повышение уровней TNF- $\alpha$ и IL-6 на 1 порядок ${ }^{2}$ увеличивает риск развития ХCH (на $60 \%$ и $68 \%$ соответственно, независимо от факторов риска ХCH). В этом исследовании у лиц с повышенным уровнем CRP (> 5 мг / л) риск последующего развития ХCH увеличивался в 2,8 раза, а при повышении уровня всех 3 маркеров системного воспаления (TNF- $\alpha$, IL-6 и CRB) - в 4,07 раза $(\mathrm{OP}=4,07$ [1,34-12,37]; $p=0,01)$, по сравнению с участниками исследования у которых уровень TNF- $\alpha$, CRP и IL-6 оставался нормальным [24].

Существенная роль системного воспаления в патогенезе ХОБЛ, ХСН и ишемической болезни сердца (ИБС) делает актуальным изучение роли противовоспалительной терапии как механизма профилактики сердечно-сосудистых осложнений у больных ХОБЛ.

\section{Особенности фармакотерапии \\ $\beta$-блокаторы}

Препараты из группы $\beta$-блокаторов являются средствами 1-й линии для терапии ХСН. Регулярное применение метопролола позволяет снизить летальность

NO - ключевой ангиопротективный фактор, отвечающий за поддержание нормального базального тонуса сосудов, подавляет пролиферацию гладкой мускулатуры сосудов и препятствует прогрессированию атеросклероза.

2 В этом исследовании были приняты 3 порядка для концентрации IL-6: < 3,12; от 3,13 до 5,27 и от 5,28 до 275 пг / мл. Уровень TNF- $\alpha$ был так же разделен на 3 порядка: 0,04-2,60; 2,61-5,00 и 5,01-40 нг / мл. 
у больных ХСН на 34 \% [25]. Аналогичные результаты были получены в исследованиях карведилола [26] и бисопролола [27]. Кроме того, препараты этой группы занимают центральное место в терапии больных, перенесших инфаркт миокарда [28], у пациентов со стенокардией [29] и гипертиреозом [30]. Таким образом, большой терапевтический потенциал $\beta$-блокаторов является серьезным аргументом для их использования у больных ХОБЛ с сопутствующими сердечно-сосудистыми заболеваниями.

С другой стороны, применение $\beta$-блокаторов при ХОБЛ вызывает обоснованные опасения. Более того, наличие ХОБЛ до сих пор рассматривается как относительное противопоказание для назначения $\beta$-блокаторов. В одном из немногих документов, описывающих принципы терапии сердечно-сосудистых заболеваний у больных ХОБЛ (Руководство по терапии артериальной гипертензии у больных бронхиальной астмой и ХОБЛ [31]), подготовленном The American College of Chest Physicians, указывается, что, несмотря на относительные противопоказания для больных ХОБЛ, $\beta$-блокаторы могут назначаться при этом заболевании с учетом ожидаемой пользы и возможного риска для больного. Однако сегодня многие эксперты полагают, что вопрос о возможности назначения селективных $\beta_{1}$-блокаторов у больных ХОБЛ следует пересмотреть в плане расширения показаний [32], т. к. безопасность этих препаратов у больных с бронхообструкцией была удовлетворительно доказана в ходе клинических исследований.

Так, опубликованный в 2005 г. Кохрейновский обзор исследований кардиоселективных $\beta$-блокаторов не выявил отрицательного влияния этих препаратов на симптомы и величину ОФВ 1 у больных ХОБЛ [33]. Кроме того, существует несколько наблюдательных исследований, которые показали, что прием $\beta$-блокаторов снижает летальность у больных ХОБЛ [34-36]. Например, в одном из последних когортных исследований с участием 2230 больных ХОБЛ было показано, что регулярный прием $\beta$-блокаторов снижает число обострений ХОБЛ и риск летального исхода у пациентов с ХОБЛ на $27 \%$ и $30 \%$ соответственно [37]. Кроме того, имеются исследования, в которых $\beta$-блокаторы показали свою безопасность даже у больных, госпитализированных в стационар по поводу обострения ХОБЛ, причем назначение этих препаратов примерно на 60 \% снижало риск гибели пациентов в условиях стационара [38].

Однако утверждать, что кардиоселективные $\beta$-блокаторы полностью безопасны для больных ХОБЛ, все же преждевременно.

Наиболее безопасным $\beta$-блокатором для применения у больных с бронхообструкцией принято считать бисопролол [39]. Тем не менее в недавно опубликованном исследовании 27 больных ХОБЛ с умеренным и тяжелым течением заболевания было показано, что этот препарат может достоверно снижать показатели ОФВ 1 у пациентов с ХОБЛ. В этом исследовании больные были рандомизированы в группы приема бисопролола и плацебо. За 4 мес. лечения ОФВ в группе плацебо увеличился в среднем на 120 мл, а в группе бисопролола, напротив, уменьшился на 70 мл $(p=0,01)$. Однако число обострений ХОБЛ в группах бисопролола и плацебо значимо не отличалось $(0,50$ и 0,31 соответственно, $p=0,44)$ [40].

Следует помнить, что ХОБЛ является заболеванием, включающим в себя множество различных фенотипов [41], в т. ч. среди больных ХОБЛ имеются пациенты с бронхиальной гиперреактивностью, для которых применение $\beta$-блокаторов может представлять определенный риск.

Несомненно, что назначение селективных $\beta$-блокаторов у больных ХОБЛ в сочетании с ХСН или перенесенным инфарктом миокарда будет благоприятно влиять на течение сердечно-сосудистой патологии и в целом безопасно для большинства больных. Однако подобное решение требует от врача дополнительной оценки безопасности и проведения контрольного спирометрического исследования. Кроме того, следует помнить, что мы не обладаем достаточными данными о безопасности $\alpha$-, $\beta$-блокаторов (карведилол), кроме того, любые $\beta$-блокаторы не следует назначать пациентам в период обострения ХОБЛ.

\section{Ингибиторы АПФ}

Активация симпатической иннервации и ренин-ангиотензиновой системы неизбежно сопровождает течение ХСН. У больных ХОБЛ это может приводить к дополнительному риску дисфункции скелетных мышц и мускулатуры респираторного тракта [42]. Кроме того, ангиотензин II может выступать в качестве провоспалительного медиатора [43].

Полиморфизм гена, кодирующего ангиотензинпревращающий фермент (АПФ), может приводить у больных ХОБЛ (гомозигот DD) к высокой легочной гипертензии [44] и нарушениям тканевой оксигенации [45]. Таким образом, назначение ингибиторов АПФ не только снижает летальность у больных $\mathrm{XCH}$, но может оказывать положительное влияние на течение ХОБЛ.

При этом важно отметить, что на эффективность ингибитора АПФ 1-го поколения каптоприла у больных ХОБЛ влияет полиморфизм гена, кодирующего АПФ. Таким образом, эффективность каптоприла у гомозигот DD существенно ниже [46], однако для эналаприла не было выявлено вариабельности эффекта в зависимости от генетических факторов [47]. В исследованиях, проведенных у больных с сочетанной патологией, эналаприл, по сравнению с плацебо, увеличивал уровень сатурации и позволял больным выполнять более высокую нагрузку на велоэргометре. Кроме того, у больных ХОБЛ ингибиторы АПФ, по-видимому, не увеличивают выраженность кашля или одышки [48].

\section{Диуретики}

Диуретики показаны всем больным ХCH, имеющим признаки задержки жидкости. Следует помнить, что при совместном назначении диуретики увеличивают риск нежелательных эффектов $\beta_{2}$-агонистов [49]. Больные с сочетанием ХСН и ХОБЛ требуют регу- 
лярного контроля уровня электролитов крови и, в первую очередь, уровня калия.

\section{ГKC}

В небольшом исследовании продолжительностью 2 нед. было показано, что ингаляционный флутиказон (1 000 мкг в сутки) и преднизолон (30 мг в сутки) по сравнению с плацебо снижают уровень циркулирующего CRB на $50 \%$ и $63 \%$ соответственно [50], что сопровождается снижением частоты сердечнососудистых симптомов. В другом аналогичном исследовании флутиказон и преднизолон через 2 нед. лечения достоверно снижали уровень растворимых рецепторов sTNF-R2 (на $24 \%$ и $26 \%$ соответсвенно) и фактор хемотаксиса моноцитов [51]. Однако положительное влияние ингаляционных ГКС на уровень CRB у больных ХОБЛ было выявлено не во всех исследованиях [52].

Различия в оценке влияние ГКС на системное воспаление у больных ХОБЛ, возможно, связаны с действием патологических механизмов, которые уменьшают ответ больных ХОБЛ на терапию кортикостероидами. В частности, было показано, что у курильщиков вообще, и у больных ХОБЛ в особенности, отмечается снижение активности гистондеацетилазы-2 [53]. Этот фермент необходим для того, что бы ГКС могли тормозить транскрипцию белков, поддерживающих системное воспаление [54]. В экспериментах in vitro было показано, что дексаметазон почти не уменьшает синтез прововоспалительных цитокинов макрофагами, выделенными у больных ХОБЛ [55]. Однако активность гистондеацетилазы-2 можно восстановить при помощи теофиллина. Было показано, что макрофаги курильщиков в присутствии теофиллина отвечают на инкубацию дексаметазона выраженным снижением синтеза IL-8 [56].

Интересно рассмотреть имеющиеся доказательства положительного влияния ГКС на риск сердечно-сосудистых заболеваний у больных ХОБЛ. Например, в крупном популяционном исследовании с участием 5648 больных ХОБЛ, включенных в канадскую базу данных Saskatchewan health services databases, было выявлено снижение риска инфаркта миокарда на 32 \% при приеме низких (50-200 мкг в сутки) доз ингаляционных ГКС [57].

Дополнительный анализ результатов исследования EUROSCOP показал, что будесонид оказывает протективное действие на течение ИБС у больных ХОБЛ (рисунок). Число больных, у которых в ходе 3-летнего наблюдения были зафиксированы проявления ИБС, в группе будесонида было почти в 3 раза меньше, чем в группе плацебо (3,0 \% и 5,3\% соответственно). Следует отметить, что различия между группами по числу проявлений ИБС стали очевидны уже в 1-е месяцы лечения [58].

Однако положительное влияние ГКС на риск острого инфаркта миокарда отмечалось далеко не во всех рандомизированных клинических исследованиях (РКИ). Так, обобщенные результаты 23 РКИ не выявили статистически значимого влияния ГКСтерапии на риск инфаркта миокарда. Но при этом

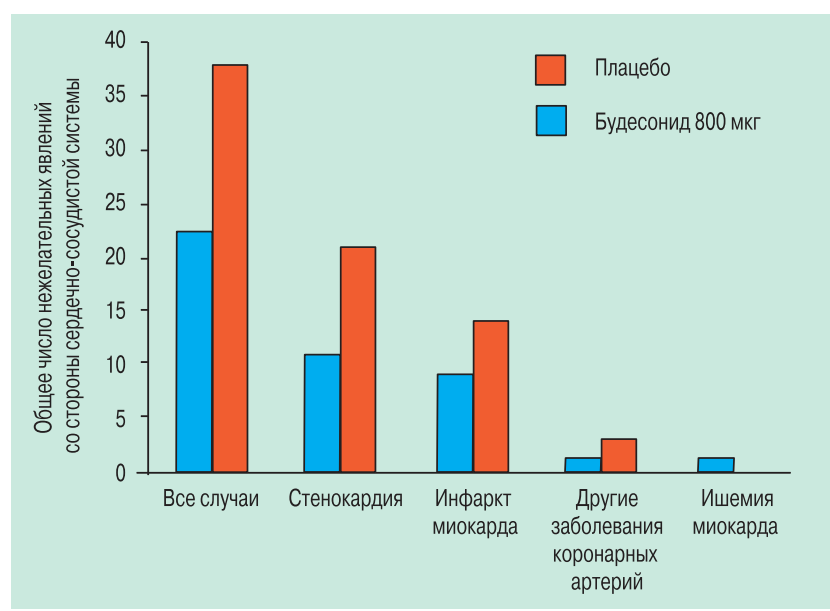

Рисунок. Проявления ИБС у больных ХОБЛ - участников исследования EUROSCOP [58]

результаты наблюдательных исследований свидетельствуют о том, что прием ГКС на $21 \%$ снижает смертность от сердечно-сосудистых причин (снижение риска $-0,79[0,72-0,86] ; p<0,0001)$. По мнению авторов, расхождение между данными РКИ и более крупными наблюдательными исследованиями требует дополнительного изучения [59].

В 10-16 \% случаев респираторная инфекция вызывает не только обострение ХОБЛ, но и декомпенсацию ХСН, а гипоксия, сопровождающая обострения ХОБЛ, отрицательно сказывается на состоянии сердечно-сосудистой системы у больных с сочетанной ХСН или ИБС [60]. В этом плане может представлять интерес опыт применения ингаляционных ГКС (будесонид) для терапии обострений ХОБЛ. Имеющиеся исследования показывают, что ингаляции будесонида через небулайзер позволяют уменьшить выраженность гипоксии уже в 1-е минуты после ингаляции [61].

\section{Статины}

Статины также способны влиять на системное воспаление и снижать уровень CRP за счет уменьшения продукции IL-6 [62], что позволяет обсуждать место этих препаратов в терапии ХОБЛ. В экспериментальных исследованиях статины уменьшали воспалительную инфильтрацию в тканях легкого. Возможно, эти препараты могут ингибировать прогрессирование эмфиземы легких, вызванную курением [63]. Фармакоэпидемиологическое исследование показало, что статины у больных ХОБЛ могут уменьшать выраженность ИБС и снижать смертность не только от сердечно-сосудистой патологии, но и от респираторных заболеваний [64]. Причем статины в комбинации с ингаляционными ГКС оказывают лучшее влияние на прогноз у больных ХОБЛ: прием только ГКС снижал шансы летального исхода от сердечнососудистых причин на $25 \%$, прием только статинов на $31 \%$, а обоих препаратов - на $61 \%$ [65].

\section{$\beta$-агонисты}

Крупное когортное исследование, в котором приняли участие 12090 больных ХОБЛ, не выявило статистически значимого увеличения риска инфаркта 
миокарда у пациентов, получавших $\beta$-агонисты короткого действия. Отношение риска инфаркта миокарда у больных, использовавших $\beta_{2}$-агонисты, составило $1,12(0,95-1,33)$, а у больных, которым эти препараты были назначены впервые, - 1,02 (0,52$2,00)$ [66]. В исследовании TORCH применение салметерола в качестве монотерапии или в составе комбинированного препарата, также не сопровождалось ростом числа сердечно-сосудистых нежелательных явлений [67].

С другой стороны, у больных ХОБЛ, исходно имеющих нарушение сердечного ритма или находящихся в состоянии гипоксии, применение $\beta_{2}$-агонистов может приводить к пароксизмальным нарушениям ритма и вызывать снижение уровня калия в плазме крови [68], в связи с этим таким больным $\beta_{2}$-агонисты следует назначать с осторожностью.

Применение длительно действующих $\beta$-агонистов в составе комбинированных препаратов представляется в целом достаточно безопасным. Данные 2 последних крупных исследований по применению комбинации будесонид / формотерол у больных ХОБЛ (SUN - 1724 участников, SHINE - 1974 участников [69]) дают наиболее точное представление о безопасности комбинированных препаратов у этих пациентов. Эти исследования предусматривали наиболее широкий набор тестов для оценки безопасности лечения, включая холтеровское ЭКГ-мониторирование, контроль уровня глюкозы и калия плазмы, офтальмологическое обследование, проведение остеоденситометрии. Данные этих исследований не выявили повышения риска нежелательных явлений при назначении будесонида / формотерола в суточных дозах 320 / 9 и 640 / 9 мкг по сравнению с плацебо.

\section{М-холинолитики}

Риск нежелательных явлений со стороны сердечнососудистой системы при применении 1-го длительно действующего М-холинолитика тиотропия долгое время был предметом обсуждения. Однако наиболее крупное исследование этого препарата UPLIFT [70], продолжавшееся 4 года, и результаты опубликованного в 2010 г. мета-анализа [71] не выявили у этого препарата нежелательного влияния на риск прогрессирования ИБС, развития инфаркта или острых нарушений мозгового кровообращения.

\section{Теофиллин}

У больных ХОБЛ следует избегать назначения теофиллина в бронхолитических дозах, т. к. этот препарат на 17-31\% увеличивает риск летального исхода [72]. Вместе с тем применение этого препарата в низких, суббронхолитических дозах (100 мкг в сутки) может повышать у больных ХОБЛ чувствительность клеток к ГКС.

\section{Заключение}

Данные, полученные в последние годы, во многом расширили и уточнили наши представления о соче- танной респираторной и сердечно-сосудистой патологии. Однако ведение таких больных по-прежнему является трудной задачей, требующей от врача ответственных и взвешенных решений.

\section{Литература}

1. Rutten F.H., Cramer M.J., Lammers J.W. et al. Heart failure and chronic obstructive pulmonary disease: an ignored combination? Eur. J. Heart Fail. 2006; 8: 706-711.

2. Huiart L., Ernst P., Suissa S. Cardiovascular morbidity and mortality in COPD. Chest 2005; 128:2640-2646.

3. Kitzman D.W., Gardin J.M., Gottdiener J.S. et al. Importance of heart failure with preserved systolic function in patients 65 years of age. CHS Research Group. Cardiovascular Health Study. Am. J. Cardiol. 2001; 87: 413-419.

4. Hawkins N.M., Petrie M.C., Jhund P.C. et al. Heart failure and chronic obstructive pulmonary disease: diagnostic pitfalls and epidemiology. Eur. J. Heart Fail. 2009; 11: 130-139

5. Milne E.N. Correlation of physiologic findings with chest roentgenology. Radiol. Clin. North. Am. 1973; 11: 17-47.

6. Hublitz U.F., Shapiro J.H. Atypical pulmonary patterns of congestive heart failure in chronic lung disease. Radiology 1969; 93: 995-1006.

7. Rutten F.H., Moons K.G., Cramer M.J. et al. Recognising heart failure in elderly patients with stable chronic obstructive pulmonary disease in primary care: cross-sectional diagnostic study. Br. Med. J. 2005; 331: 1379.

8. Vizza C.D., Lynch J.P., Ochoa L.L. et al. Right and left ventricular dysfunction in patients with severe pulmonary disease. Chest 1998; 113: 576-583.

9. Marcu C.B., Beek A.M., van Rossum A.C. Cardiovascular magnetic resonance imaging for the assessment of right heart involvement in cardiac and pulmonary disease. Heart Lung Circ. 2006; 15: 362-370.

10. Silver M.A., Maisel A., Yancy C.W. et al. BNP Consensus Panel 2004: a clinical approach for the diagnostic, prognostic, screening, treatment monitoring, and therapeutic roles of natriuretic peptides in cardiovascular diseases. Congest. Heart Fail. 2004; 10 (Suppl. 3): 1-30.

11. Light R.W., George R.B. Serial pulmonary function in patients with acute heart failure. Arch. Intern. Med. 1983; 143: 429-433.

12. Petermann $W$., Barth J., Entzian P. Heart failure and airway obstruction. Int. J. Cardiol. 1987; 17: 207-209.

13. Sin D.D., LieLing Wu., Man S.F.P. The relationship between reduced lung function and cardiovascular mortality. Chest 2005; 127 (6): 1952-1959.

14. Dahl M., Vestbo J., Lange P. et al. C-reactive protein as a predictor of prognosis in chronic obstructive pulmonary disease. Am. J. Respir. Crit. Care Med. 2007; 2007: 250-255.

15. Gan W.Q., Man S.F., Sin D.D. The interactions between cigarette smoking and reduced lung function on systemic inflammation. Chest 2005; 127: 558-564.

16. Guerra S., Sherrill D.L., Venker C. et al. Chronic bronchitis before age 50 years predicts incident airflow limitation and mortality risk. Thorax 2009; 64: 894-900.

17. Gan W.Q., Man S.F., Senthilselvan A., Sin D.D. The association between chronic obstructive pulmonary disease and systemic inflammation a systematic review and a metaanalysis. Thorax 2004; 59: 574-580.

18. Walter R.E., Wilk J.B., Larson M.G. et al. Systemic inflammation and COPD: the framingham heart study. Chest 2008; 133: 19-25.

19. Aronson D., Roterman I., Yigla M. et al. Inverse association between pulmonary function and $\mathrm{C}$-reactive protein in 
apparently healthy subjects. Am. J. Respir. Crit. Care Med. 2006: 174: 626-632.

20. Verma S., Li S.H., Badiwala M.V. et al. Endothelin antagonism and interleukin- 6 inhibition attenuate the proatherogenic effects of C-reactive protein. Circulation 2002; 105: 1890-1896.

21. Sin D.D., Man S.F.P. Why are patients with chronic obstructive pulmonary disease at increased risk of cardiovascular diseases? Circulation 2003; 107:1 514-1519.

22. Venugopal S.K., Devaraj S., Yuhanna I. et al. Demonstration that C-reactive protein decrease eNOS expression and bioactivity in human aortic endothelial cells. Circulation 2002; 106: 1439-1441.

23. Torzewski M., Rist C., Mortensen R.F. et al. C-reactive protein in the arterial intima. Role of $\mathrm{C}$-reactive protein receptor-dependent monocyte recruitment in atherogenesis. Arterioscler. Thromb. Vasc. Biol. 2000; 20: 2094-2099.

24. Vasan R.S., Sullivan L.M., Roubenoff R. et al. Inflammatory markers and risk of heart failure in elderly subjects without prior myocardial infarctionthe framingham heart study. Circulation 2003; 107; 1486-1491.

25. MERIT-HF Study Group. Effect of metoprolol CR / XL in chronic heart failure: Metoprolol CR / XL Randomised Intervention Trial in Congestive Heart Failure (MERITHF). Lancet 1999; 353: 2001-2007.

26. Packer M., Fowler M.B., Roecker E.B. et al. Effect of carvedilol on the morbidity of patients with severe chronic heart failure: results of the Carvedilol Prospective Randomized Cumulative Survival (COPERNICUS) study. Circulation 2002; 106: 2194-2187.

27. CIBIS-II Investigators and Committees. The Cardiac Insufficiency Bisoprolol Study II (CIBIS-II): a randomised trial. Lancet 1999; 353: 9-13.

28. Freemantle N., Cleland J., Young P. et al. Beta-blockade after myocardial infarction: systematic review and meta regression analysis. Br. Med. J. 1999; 318: 1730-1737.

29. Heidenreich P.A., McDonald K.M., Hastie T. et al. Metaanalysis of trials comparing beta-blockers, calcium antagonists, and nitrates for stable angina. J.A.M.A. 1999; 281: 1927-1936.

30. Kvetny J., Frederikesen P.K., Jacobsen J.G. et al. Propranolol in the treatment of thyrotoxicosis. A randomized doubleblind study. Act. Med. Scand. 1981; 209: 389-392.

31. Dart R.A., Gollub S., Lazar J. et al. Treatment of systemic hypertension in patients with pulmonary diseases: COPD and asthma. Chest 2003; 123: 222-243.

32. $A u$ D.H. Use of beta-blockers in patients with COPD. Thorax 2008; 63: 296-298.

33. Salpeter S., Ormiston T., Salpeter E. Cardioselective betablockers for chronic obstructive pulmonary disease. Cochrane Database Syst. Rev. 2005; (4): CD003566.

34. Au D.H., Bryson C.L., Fan V.S. et al. Beta-blockers as single-agent therapy for hypertension and the risk of mortality among patients with chronic obstructive pulmonary disease. Am. J. Med. 2004; 117: 925-931.

35. Andrus M.R., Holloway K.P., Clark D.B. Use of beta-blockers in patients with COPD. Ann. Pharmacother. 2004; 38: $142-145$.

36. Chen J., Radford M.J., Wang Y. et al. Effectiveness of betablocker therapy after acute myocardial infarction in elderly patients with chronic obstructive pulmonary disease or asthma. J. Am. Coll. Cardiol. 2001; 37: 1950-1956.

37. Rutten F.H. Beta-blockers may reduce mortality and risk of exacerbations in patients with chronic obstructive pulmonary disease. Arch. Intern. Med. 2010; 170 (10): $880-887$.
38. Dransfield M.T., Rowe S.M., Johnson J.E. et al. Use of blockers and the risk of death in hospitalised patients with acute exacerbations of COPD. Thorax 2008; 63: 301-305.

39. Цветкова, О. А. Эффективность применения кардиоселективного бета1-адреноблокатора бисопролола у больных хронической обструктивной болезнью легких в сочетании с ишемической болезнью сердца. Тер. арх. 2007; 79 (3): 25-29.

40. Hawkins M.M., MacDonald M.R., Petrie M.C. et al. Bisoprolol in patients with heart failure and moderate to severe chronic obstructive pulmonary disease: a randomized controlled trial. Eur. J. Heart Fail. 2009: 11, 684-690.

41. Han M.K., Agusti A., Calverley P.M. et al. COPD phenotypes: the future of COPD. Am. J. Respir. Crit. Care Med. 2010; 182: 598-604.

42. Andreas S., Anker S.D., Scanlon P.D., Somers V.K.: Neurohumoral activation as a link to systemic manifestations of chronic lung disease. Chest 2005; 128: 3618-3624.

43. Dandona P., Dhindsa S., Ghanim H., Chaudhuri A. Angiotensin II and inflammation: the effect of angiotensin-converting enzyme inhibition and angiotensin II receptor blockade. J. Hum. Hypertens 2007; 21: 20-27.

44. Kanazawa H., Okamoto T., Hirata K., Yoshikawa J. Deletion polymorphisms in the angiotensin converting enzyme gene are associated with pulmonary hypertension evoked by exercise challenge in patients with chronic obstructive pulmonary disease. Am. J. Respir. Crit Care. Med. 2000; 162: $1235-1238$.

45. Kanazawa H., Otsuka T., Hirata K., Yoshikawa Association between the angiotensin-converting enzyme gene polymorphisms and tissue oxygenation during exercise in patients with COPD. Chest 2002; 121: 697-701.

46. Kanazawa H., Hirata K., Yoshikawa J. Effects of captopril administration on pulmonary haemodynamics and tissue oxygenation during exercise in ACE gene subtypes in patients with COPD: a preliminary study. Thorax 2003; 58: 629-631.

47. Marco F.D., Guazzi M., Vicenzi M. Effect of enalapril on exercise cardiopulmonary performance in chronic obstructive pulmonary disease: A pilot study. Pulmonary Pharmacology \& Therapeutics 2010; 23: 159-164.

48. Anker S.D. Prognostic importance of weight loss in chronic heart failure and the effect of treatment with angiotensinconverting-enzyme inhibitors: an observational study. Lancet 2003; 361:1077-1083.

49. Lipworth B.J. et al. Prior treatment with diuretic augments the hypokalaemic and electrocardiographic effects of inhaled albuterol. Am. J. Med. 1989; 86: 653-657.

50. Sin D.D., Lacy P., York E., Man S.F. Effects of fluticasone on systemic markers of inflammation in chronic obstructive pulmonary disease. Am. J. Respir. Crit. Care Med. 2004; 170: 760-765.

51. Man S.F. P., Zhang X. The effects of inhaled and oral corticosteroids on serum inflammatory biomarkers in COPD: an exploratory study. Ther. Adv. Respir. Dis. 2009; 3 (2): 73-80.

52. Sin D.D. The effects of fluticasone with or without salmeterol on systemic biomarkers of inflammation in chronic obstructive pulmonary disease. Am. J. Respir. Crit. Care Med. 2008; 177: 1207-1214.

53. Ito K., Ito M., Elliott W.M. et al. Decreased histone deacetylase activity in chronic obstructive pulmonary disease. N. Eng. J. Med. 2005; 352: 1967-1976.

54. Barnes P.J., Adcock I.M., Ito K. Histone acetylation and deacetylation: importance in inflammatory lung diseases. Eur. Respir. J. 2005; 25: 552-563. 
55. Culpitt S.V., de Matos C., Russell R.E. et al. Effect of theophylline on induced sputum inflammatory indices and neutrophil chemotaxis in COPD. Am. J. Respir. Crit. Care Med. 2002; 165: 1371-1376.

56. Cosio B.G., Tsaprouni L., Ito K. et al. Theophylline restores histone deacetylase activity and steroid responses in COPD macrophages. J. Exp. Med. 2004; 200: 689-695.

57. Huiart L., Ernst P., Panouil X., Suissa S. Low-dose inhaled corticosteroids and the risk of acute myocardial infarction in COPD. Eur. Respir. J. 2005; 25: 634-639.

58. Lofdahl C.-G., Postma D.S., Pride N.B. et al. Possible protection by inhaled budesonide against ischaemic cardiac events in mild COPD. Eur. Respir. J. 2007; 29: 1115-1119.

59. Loke Y.K., Kwok C.S., Singh S. Risk of myocardial infarction and cardiovascular death associated with inhaled corticosteroids in COPD. Eur. Respir. J. 2010; 35: 1003-1021.

60. Nieminen M.S. EuroHeart Failure Survey II (EHFS II): a survey on hospitalized acute heart failure patients: description of population. Eur. Heart J. 2006; 27: 2725-2736.

61. Mirici A., Meral M., Akgun M. Comparison of the efficacy of nebulised budesonide with parenteral corticosteroids in the treatment of acute exacerbations of chronic obstructive pulmonary disease. Clin. Drug Invest. 2003; 23: 55-62.

62. Hothersall E., McSharry C., Thomson N.C. Potential therapeutic role for statins in respiratory disease. Thorax 2006; 61: 729-734.

63. Lee J.-H., Lee D.-S., Kim E.-K. et al. Simvastatin inhibits cigarette smoking-induced emphysema and pulmonary hypertension in rat lungs. Am. J. Respir. Crit. Care Med. 2005; 172: 987-993.

64. Mancini G.B., Etminan M., Zhang B. et al. Reduction of morbidity and mortality by statins, angiotensin-converting enzyme inhibitors, and angiotensin receptor blockers in patients with chronic obstructive pulmonary disease. J. Am. Coll. Cardiol. 2006; 47: 2554-2560.
65. Soyseth V., Brekke P.H., Smith P. et al. Statin use is associated with reduced mortality in COPD. Eur. Respir. J. 2007; 29: 279-283.

66. Suissa S., Assimes T., Ernst P. Risk of acute myocardial infaction Inhaled short acting - agonistis use in COPD and the risk of acute myocardial infaction. Thorax 2003; 58: 43-46.

67. Calverley P.M.A., Anderson J.A., Celli B. Cardiovascular events in patients with COPD: TORCH Study results. Thorax 2010; 65: 719-725.

68. Cazzola M., Imperatore F., Salzillo A. Cardiac effects of formoterol and salmeterol in patients suffering from COPD with preexisting cardiac arrhythmias and hypoxemia. Chest 1998; 114: 411-415.

69. Tashkin D.P., Rennard S.I., Martin P. et al. Efficacy and safety of budesonide and formoterol in one pressurized metered-dose inhaler in patients with moderate to very severe chronic obstructive pulmonary disease: results of a 6-month randomized clinical trial. Drugs 2008; 68 (14): 1975-2000.

70. Tashkin D.P., Celli B., Senn S. et al. A 4-year trial of tiotropium in chronic obstructive pulmonary disease. N. Eng. J. Med. 2008; 359: 1543-1554.

71. Celli B., Cote C.G., Marin J.M. et al. Cardiovascular safety of tiotropium in patients with COPD. Chest 2010; 137 (1): 20-30.

72. Ford P.A. Treatment effects of low-dose theophylline COPD combined with an inhaled corticosteroid. Chest 2010; 137 (6): $1338-1344$.

Информация об авторе

Архипов Владимир Владимирович - д. м. н., проф. кафедры клинической фармакологии и пропедевтики внутренних болезней Первого МГМУ им. И.М.Сеченова; тел. 966-54-14; e-mail: 9665414@gmail.com

Поступила 02.12.10 () Архипов В.В., 2010

УдК [616.24-036.12-06:616.12-008.46]-085 


\section{Пульмикорт द. Суспензия иткс для небулайзерной терапии}

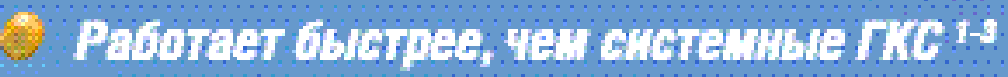

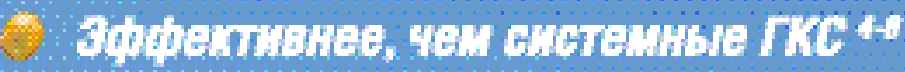

- Уиикапьный профиив безопвавновт"

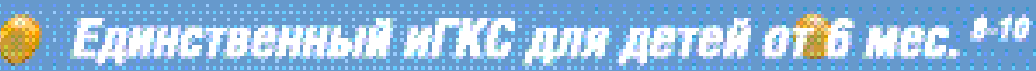

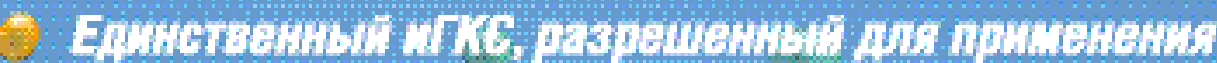

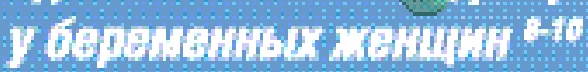

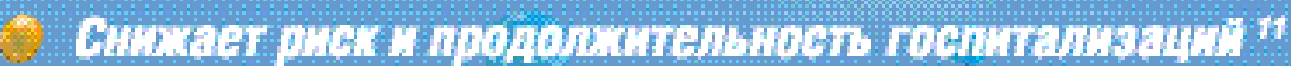

$\infty$

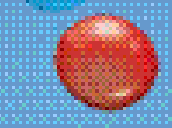

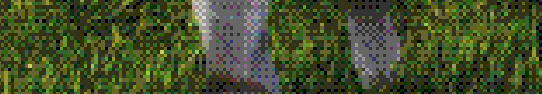

$1309 x^{2}=$
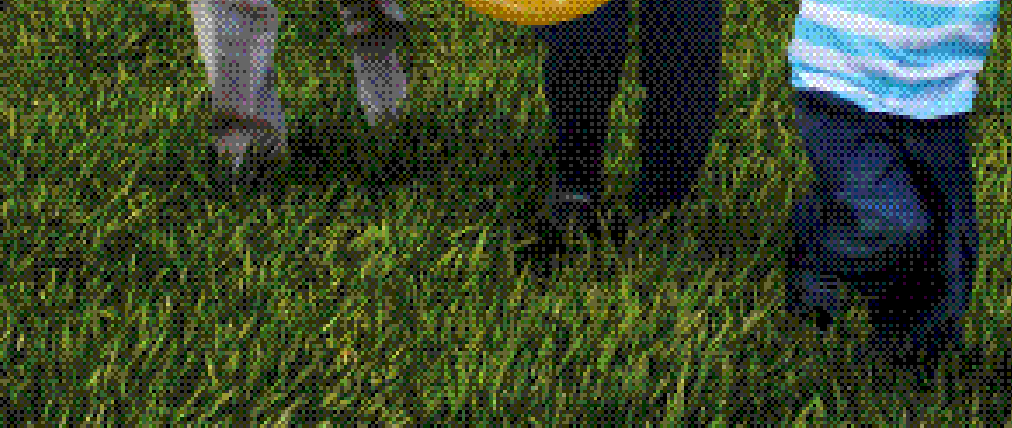

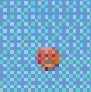
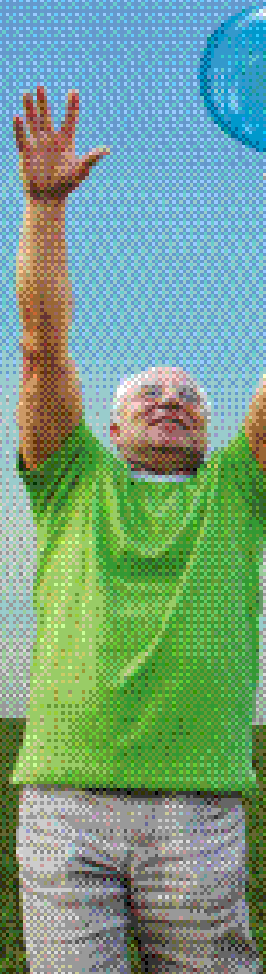

$+\frac{1}{2}+\frac{1}{2}$

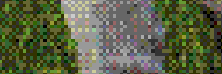

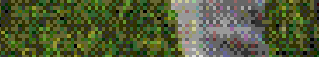

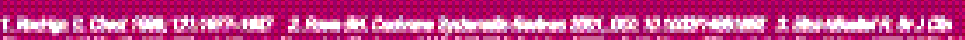

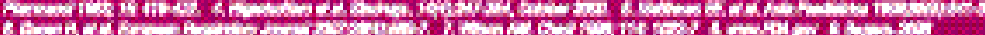

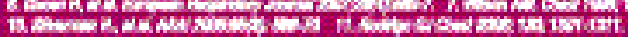

Астразенека $\%$

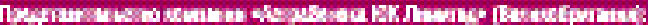

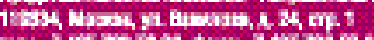

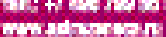

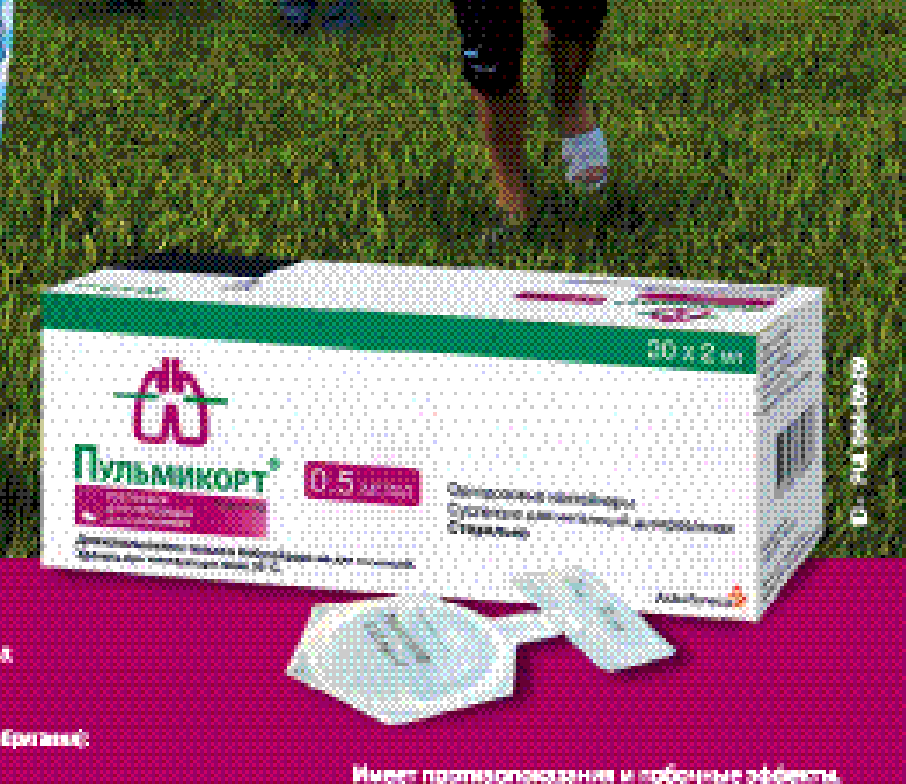

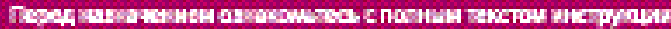

